\title{
Aplicação do índice de precipitação normalizada nos casos de ENOS canônico e Modoki ocorridos na bacia hidrográfica Aguapeí-Peixe/SP
}

A complexidade na definição de seca tem sido um obstáculo para a detecção dos impactos inicias, bem como o correto monitoramento desse fenômeno. Desse modo o Índice de Precipitação Normalizada mostrou-se capaz de quantificar o déficit ou excesso de precipitação em diversas escalas temporais, permitindo comparações entre regiões com diferentes características climáticas. Objetivou-se neste trabalho identificar e quantificar os eventos extremos ocorridos na bacia hidrográfica Aguapeí-Peixe, e simultaneamente, relacionar as possíveis causas destes extremos com os tipos de ENOS que influencia na pluviometria da região. Foram utilizados dados pluviométricos entre 1958 a 2013 de oito estações da Bacia, obtidos da Agência Nacional das Águas. Neste período foram identificados através da aplicação do Índice de Precipitação Normalizada (SPI) uma maior periodicidade de secas, entretanto os eventos de chuvas foram mais intensos. Quando relacionados as classes dos eventos identificados com os tipos de ENOS, constatou-se que em anos de El Niño Canônico há uma maior possibilidade de ocorrência de chuvas extremas, assim como, em La Niña Canônica para as secas leves. Conclui-se que a associação entre o SPI e os tipos de ENOS mostrou-se relevante para os estudos de previsões climáticas podendo auxiliar os diferentes setores evitando os transtornos causados por extremos de precipitação.

\section{Application of the normalized precipitation index in canonical and Modoki ENSO cases in the Aguapei-Peixe/SP watershed}

\begin{abstract}
The complexity in the definition of drought has been an obstacle for the detection of the initial impacts, as well the correct monitoring of this phenomenon. Therefore, the Standard Precipitation Index showed able to quantify the deficit or excess of rainfall in diverse temporal scales, allowing comparisons between regions with different climatic characteristics. The objective of this study was to identify and quantify the extreme events occurring in the hydrographic basins Aguapei-Peixe, and simultaneously to relate possible causes of these extremes with the types of ENSO that influence rainfall in the region. There were used rainfal data from 1958 to 2013 of eight stations in the hydrographic basin, obtained from the National Water Agency. In this period were identified through the application of Standard Precipitation Index (SPI) a greater periodicity of droughts, among the events of rains were more intense. When related as classes of events identified by the SPI with ENSO types, it was found that in EI Niño Canonic years there is a greater possibility of occurrence of extreme rains, as well as in La Niña Canonic for light droughts. Conclude that the association between SPI and ENSO types has proved to be relevant for the studies of climate predictions and can help the different sectors avoiding the disturbances caused by extremes of rainfall.
\end{abstract}

Keywords: Standard Precipitation Index; Extreme Rainfall; Weather Forecast.

Topic: Meteorologia, Climatologia e Mudanças Climáticas

Reviewed anonymously in the process of blind peer.
Received: 10/02/2018

Approved: $24 / 03 / 2018$
Osmar Evandro Toledo Bonfim

Universidade Federal de Alagoas, Brasil

http://lattes.cnpq.br/0484953092563459

osmartoledob@gmail.com

\section{Djane Fonseca da Silva}

Universidade Federal de Alagoas, Brasil

http://lattes.cnpq.br/4845745142696485

djane.silva@icat.ufal.br

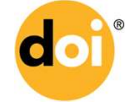

DOI: 10.6008/CBPC2179-6858.2018.003.0007
Referencing this:

BONFIM, O. E. T.; SILVA, D. F.. Aplicação do índice de precipitação normalizada nos casos de ENOS canônico e Modoki ocorridos na bacia hidrográfica Aguapeí-Peixe/SP. Revista Ibero Americana de Ciências Ambientais, v.9, n.3, p.83-94, 2018. DOI: http://doi.org/10.6008/CBPC2179-6858.2018.003.0007 


\section{INTRODUÇÃO}

Os avanços tecnológicos permitem hoje que a humanidade, com auxílio da tecnologia, enfrente melhor os perigos decorrentes dos eventos extremos. Por exemplo, as inundações que ultrapassaram e romperam diques e barragens em New Orleans, por ocasião do Furacão Katrina em 2005, nos Estados Unidos e o terremoto de Kobe no Japão em 1995, os quais afetaram milhares de vítimas, demonstram que muitas vezes os fenômenos naturais surpreendem até mesmo as nações mais bem preparadas para enfrentá-los (SILVA, 2014).

Além da intensidade dos fenômenos naturais, o acelerado processo de urbanização verificado nas últimas décadas, em várias partes do mundo, inclusive no Brasil, levou ao crescimento das cidades, muitas vezes, em áreas impróprias à ocupação, aumentando as situações de perigo e de risco aos desastres naturais (SCHEUREN et al., 2008). Assim, diversos estudos (DANTAS et al., 2007; MARENGO, 2008; SILVA, 2009) indicam que a variabilidade climática atual, com tendência para o aquecimento global, está associada a um aumento de extremos climáticos.

$\mathrm{Na}$ tentativa de quantificar e caracterizar os eventos extremos de seca e chuva nas diferentes regiões do globo, foram criados índices capazes de identificar tais eventos. McKee et al. (1993) propuseram o Índice de Precipitação Normalizada (SPI), para quantificar o déficit de precipitação em diversas escalas de tempo. A versatilidade do SPI está na simplicidade do seu cálculo e na eficácia de identificar eventos secos e chuvosos em diferentes escalas de tempo $(3,6,12$ meses, etc), que auxilia no monitoramento da dinâmica temporal desses eventos, isto é, o desenvolvimento e declínio.

O SPI vem sendo muito utilizado por instituições de pesquisa e órgãos governamentais para monitoramento de secas e tem se mostrado como uma ferramenta útil devido sua flexibilidade, simplicidade de cálculo e interpretação (MCKEE et al., 1993; HAYES et al., 1999). Esse índice requer interpretações diferentes de acordo com sua escala de tempo (BLAIN et al., 2007), pois o SPI de um mês reflete as condições de curto prazo e sua aplicação pode estar relacionada com a umidade do solo, enquanto que o SPI de três meses fornece uma estimativa sazonal da precipitação. Já o SPI de seis a nove meses indica tendências de médio prazo nos padrões de precipitação e o SPI de doze meses reflete os padrões de precipitação de longo prazo, geralmente vinculados a vazões, níveis de reservatórios e de água subterrânea (ULIANA et al., 2015).

Santos et al. (2017), utilizando o SPI para a Amazônia Oriental, detectaram que sua região nordeste possui mais eventos secos que chuvosos. Nas demais regiões (central e sul) a situação é inversa, isto é, existem mais eventos de chuva, porém de pouca duração. Adicionalmente, a região sul apresentou seca mais severa e prolongada. Os autores associaram os eventos citados à variabilidade climática que ocorre nos Oceanos Atlântico (Gradiente do Atlântico) e Pacífico (ENOS).

Os Eventos extremos em consequência de acarretar perdas econômicas e de vida, têm sido cada vez mais estudados. Para o Sudeste do Brasil alguns estudos relacionam os extremos de precipitação com a variabilidade interanual e intrasazonal (GRIMM et al., 2004; MUSA et al., 2009), com a zona de convergência do Atlântico Sul (ROSEGHINI, 2007; ALVARENGA, 2012) e também com a orografia (LIMA et al., 2011). O 
Oeste Paulista, está exposto à maioria dos fenômenos meteorológicos e climáticos que afetam o Brasil devido sua área localizar-se em uma região de transição climática (GRIMM, 2002).

As Bacias hidrográficas do Rio Aguapeí e do Rio do Peixe, situadas no Oeste paulista, são caracterizadas como agropecuárias em razão da pecuária extensiva e do plantio da cana-de açúcar que são importantes para a economia da região. Anualmente intensas chuvas que ocorrem especialmente no verão, provocam erosões, inundações e deslizamentos de terra que afetam principalmente a infraestrutura da região, tal como os bloqueios de rodovias e rupturas de pontes. Para o setor agrícola o excesso ou a falta de chuva afeta tanto o plantio como a colheita das culturas como amendoim, café, cana de açúcar e hortaliças. Desta forma, objetiva-se utilizar o SPI para identificar e quantificar os eventos extremos ocorridos na Bacia hidrográfica Aguapeí-Peixe, entre o período de 1958 a 2013, ao mesmo tempo, busca-se as possíveis causas destes extremos identificados a partir da relação dos tipos de ENOS que influencia na pluviometria da região.

\section{METODOLOGIA}

Foram utilizados dados pluviométricos de 8 estações representativas espacialmente da Bacia hidrográfica Aguapeí-Peixe, Estado de São Paulo, provenientes da Agência Nacional das Água (ANA). Com esses dados foram criados gráficos de séries temporais de SPI para identificação e quantificação dos eventos extremos, além de classifica-los de acordo com a sua intensidade.

O cálculo do SPI se inicia determinando uma função de densidade de probabilidade que descreve as séries temporais. A distribuição gama possui bom ajuste para variáveis contínuas que tenham limite inferior ou igual a zero e não possuem limite superior, por isso, é largamente utilizada para o estudo de séries históricas de precipitação Wilks (2006, citado por SANTOS et al., 2017).

A função gama é dada por:

$$
g(x)=\frac{X^{\alpha-1} * e^{\frac{-x}{\beta}}}{\beta^{\alpha} \Gamma(\alpha)} \text { para } X>0
$$

, sendo: $\alpha>0$ parâmetro de forma; $\beta>0$ parâmetro de escala; $x>0$, a quantidade de precipitação $(\mathrm{mm})$ e $\Gamma(\alpha)$ a função gama completa. Para

estimativa dos parâmetros $\alpha$ e $\beta$ da distribuição gama utilizou-se o método de

$$
\alpha=\frac{1}{4 A}\left(1+\sqrt{1+\frac{4 A}{3}}\right) \mathrm{e} \hat{\beta}=\frac{\bar{x}}{\alpha},
$$

, sendo $\bar{x}$ a precipitação média e

$$
A=\ln (\bar{x})-\frac{\Sigma \ln (x)}{n},
$$

Deste modo a distribuição acumulativa é então transformada em distribuição probabilidade normal com média igual a zero e desvio padrão igual a um. Em seguida, a probabilidade acumulada de ocorrência de cada valor mensal é estimada. Aplica-se a essa probabilidade a função normal inversa para encontrar o valor do SPI. O SPI nada mais é que a diferença da precipitação observada menos a média do intervalo de tempo

específico, dividida pelo desvio padrão, conforme equação (Santos et al., 2017): $\quad S P I=Z_{i}=\frac{\left(P_{i}-\bar{P}_{i}\right)}{\sigma_{i}}$.Sendo sua classificação dada pelas informações da Tabela 01. 
Tabela 1: Classificação dos períodos secos e chuvosos.

\begin{tabular}{|l|l|}
\hline Valores de SPI & Classes \\
\hline$<-2,00$ & Seca Extrema \\
\hline$-1,99$ a $-1,50$ & Seca Severa \\
\hline$-1,49$ a $-1,00$ & Seca Moderada \\
\hline$-0,99$ a $-\mathbf{0 , 4 9}$ & Seca Leve \\
\hline$-0,48$ a 0,49 & Quase normal \\
\hline 0,50 a 0,99 & Chuva Leve \\
\hline 1,00 a 1,49 & Chuva moderada \\
\hline 1,50 a 1,99 & Chuva Severa \\
\hline$>2,00$ & Chuva Extrema \\
\hline
\end{tabular}

Fonte: Modificado de McKee et al. (1993).

Após a caracterização dos eventos através da aplicação do SPI (Tabela 1), os mesmos serão relacionados com os anos definidos como El Niño (EN) ou La Niña (LN), Canônico ou Modoki, a fim averiguar a influência dos diferentes tipos de ENOS na ocorrência de eventos extremos. A classificação dos ENOS Canônico e Modoki foi apresentado por Tedeschi (2013) através de medições das anomalias de temperatura da superfície do mar (TSM) na região do Oceano Pacífico Central baseado no método de Ashok et al. (2007), e os resultados estão expressos na tabela 02.

Tabela 02: Anos ENOS Canônico e Modoki no período de 1979 a 2009. Valores em negrito são coincidentes nas duas categorias.



Fonte: Ashok et al. (2007).

\section{RESULTADOS E DISCUSSÃO}

Na quantificação e caracterização dos eventos extremos na Bacia Hidrográfica Aguapeí-Peixe através da aplicação do índice de SPI, os resultados mostraram que os eventos de secas foram os mais frequentes em todas as séries analisadas, em média, com $37,4 \%$ dos eventos extremos; todavia os anos normais totalizaram, em média 36,7\%, respaldando os trabalhos de Barra et al. (2002), Macedo et al. (2010) e Santos et al. (2017).

Entretanto há uma tendência de aumento de precipitação em toda a Bacia (BONFIM et al., 2017a), fato que resulta de um aumento na intensidade e não na frequência das chuvas extremas, corroborando com Marengo (2008). Na análise de distribuição de frequência do SPI para Garça (Figura 1a), observou-se 9 ocorrências de seca severa, 61 de seca moderada e 184 de seca leve; totalizando 254 eventos, que corresponde a $37,8 \%$ dos eventos, contudo não houve registro de seca extrema (valores de SPI <-2,0). $\mathrm{Na}$ distribuição de eventos de chuvas foram notados 63 episódios de chuva leve, 48 de chuva moderada, 21 de chuva severa e 34 de chuva extrema; totalizando 166 ocorrências que corresponde a $24,7 \%$ dos eventos. 
Para a cidade de Bastos (Figura 1b), a distribuição de frequência do SPI quantificou 12 ocorrências de seca severa, 77 de seca moderada e 161 de seca leve; totalizando 250 ocorrências, que representa 37,2\% dos eventos. Semelhante à Garça, não houve registro de seca extrema na estação pluviométrica de Bastos. Na distribuição de eventos de chuvas notou-se 69 ocorrências de chuva leve, 46 de chuva moderada, 30 de chuva severa e 27 de chuva extrema; um total de 172 episódios de eventos de chuvas, que totaliza 25,42\%.

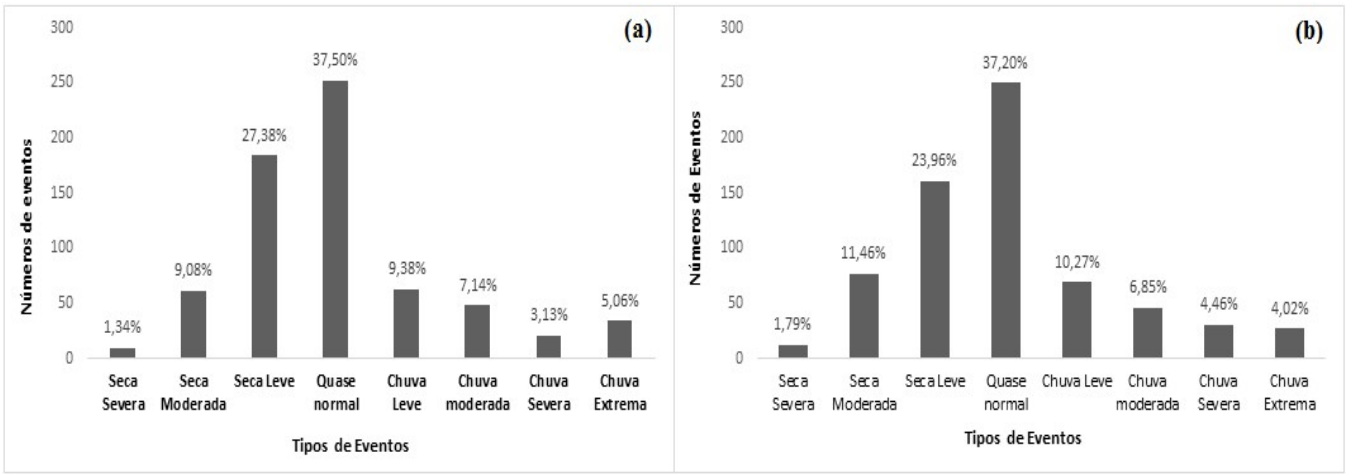

Figura 1: Distribuição de frequência SPI (a) Garça (b) Bastos.

Na análise da série temporal do SPI para cidade de Garça (Figura 2a), houve demasiada alternância dos escores do SPI que impossibilitou a ocorrência de períodos sequentes de secas ou chuvas, como mostrado nos trabalhos de Macedo et al. (2010) e Santos et al. (2017). O período mais longo de seca ocorreu entre dezembro/1967 a outubro/1969 persistindo por 23 meses, período este que se associa a fase fria da Oscilação Decenal do pacífico (ODP) ocasionando a redução da precipitação segundo Molion (2005) e Prestes et al. (2010). Este período associa-se também a eventos de El Niño Oscilação Sul (ENOS), na mesma fase (La Niña 1967/68), reduzindo a precipitação (COSTA et al., 2015) e em fases opostas (El Niño 1968/69) causando anomalias fracas e mal definidas de precipitação (GERSHUNOV et al., 1998; ANDREOLI et al., 2005; SILVA et al., 2012).

Já o maior período sequencial de chuvas foi verificado de outubro/1975 a abril/1977 permanecendo por 19 meses, em que se verifica prevalência de anos de EI Niño associado a fase quente da ODP, o que para o Sudeste do Brasil significa incremento de precipitação de acordo com Andreoli et al. (2005) e Kayano et al. (2008). A estação pluviométrica de Garça e a estação pluviométrica de Bastos pertencem ao mesmo grupo climático, ou seja, possuem comportamento semelhante em suas séries de precipitação (BONFIM et al., 2017b).

Portanto, a série temporal do SPI da cidade de Bastos (Figura 2b) possui períodos sequentes de chuvas e secas similares à série temporal de Garça. O maior período continuo de seca em Bastos ocorreu entre fevereiro/1968 a agosto/1969, já o período sequencial de chuvas ocorreu de outubro/1975 a outubro/1976, ambos os períodos foram menores quando comparados a estação de Garça. Os eventos de chuva extrema mais intensos para estação de Garça (Figura 2a) ocorreram em março/1962 e julho/2007 em que os valores de SPI $(>2,0)$ foram superiores a 4 . Já a estação de Bastos (Figura 2b) apresentou picos de chuva extrema em Julho/1966 e Julho/2007. 


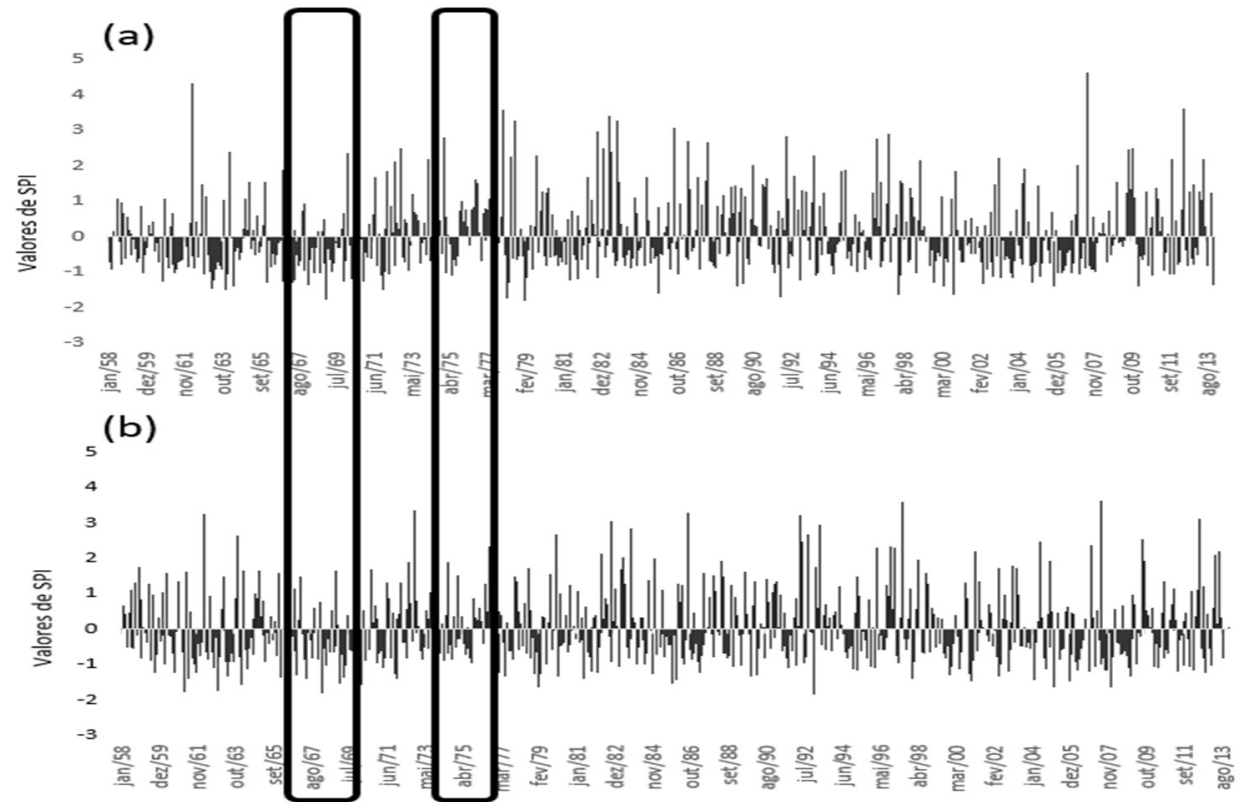

Figura 2: (a) Serie Temporal SPI para Garça (SP). (b) Serie Temporal SPI para Bastos (SP), compreendendo o período de 1958 a 2013).

Para a cidade de Guararapes (Figura 3a), a distribuição de frequência do SPI quantificou 9 ocorrências de seca severa, 75 de seca moderada e 175 de seca leve, porém sem registro de seca extrema; totalizando 259 ocorrências, que corresponde a 38,54\% dos eventos. Na distribuição de eventos de chuvas notou-se 64 ocorrências de chuva leve, 47 de chuva moderada, 30 de chuva severa e 35 de chuva extrema; um total de 176 registros, equivalente a $26,2 \%$ dos eventos.

Na análise de distribuição de frequência do SPI para Queiroz (Figura 3b), observou-se 1 ocorrência de seca extrema, 19 ocorrências de seca severa, 68 de seca moderada e 155 de seca leve; totalizando 243 eventos, que corresponde a $36,16 \%$ dos episódios na estação de Queiroz. Na quantificação de eventos de chuvas foram apontados 80 episódios de chuva leve, 45 de chuva moderada, 28 de chuva severa e 26 de chuva extrema; totalizando 179 ocorrências, que representa 26,64\% dos eventos.

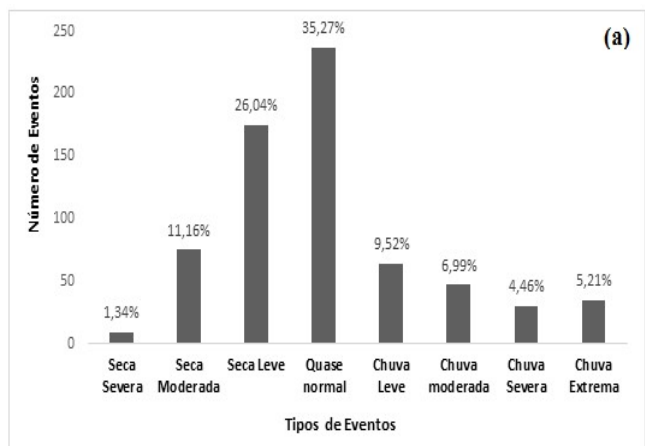

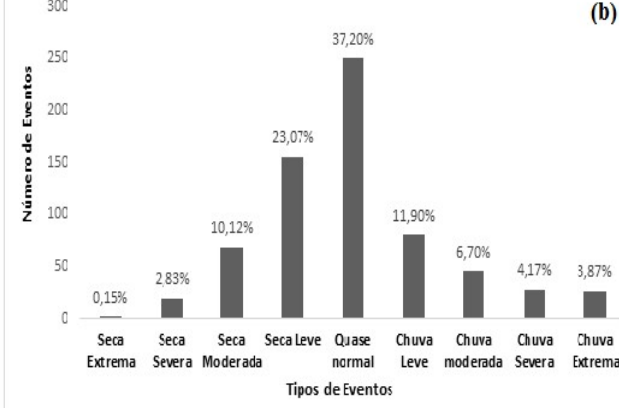

Figura 3: Distribuição de frequência SPI. (a) Guararapes (b) Queiroz.

$\mathrm{Na}$ análise da série temporal do SPI para Guararapes (Figura 4a) notou-se um período prolongado de secas com duração de 35 meses, ocorrendo entre novembro/1966 a setembro/1969, coincidindo com a fase negativa da ODP, proporcionando redução na precipitação de acordo com Molion (2005) e Prestes et al. (2010). Na série temporal do SPI para Queiroz (Figura 4b), que possui comportamento semelhante a Guararapes (BONFIM et al., 2017b), não foi possível observar este mesmo período prolongado de secas 
devido a falha de dados de precipitação disponível para esta estação. Porém foi possível identificar um período semi sequencial de secas entre maio/1994 a outubro/1996 presente em ambas as séries.

Os eventos de chuva extrema mais intensos na estação de Guararapes (Figura 4a) ocorreram em Agosto/2009 e junho/2012 atingindo valores de SPI acima de 3,5. Esses mesmos períodos também foram encontrados entre os valores de chuva extrema para a estação de Queiroz, em que os valores de SPI ficaram próximos de 5 em junho/2012, demostrando que as chuvas extremas foram mais intensas na estação de Queiroz.

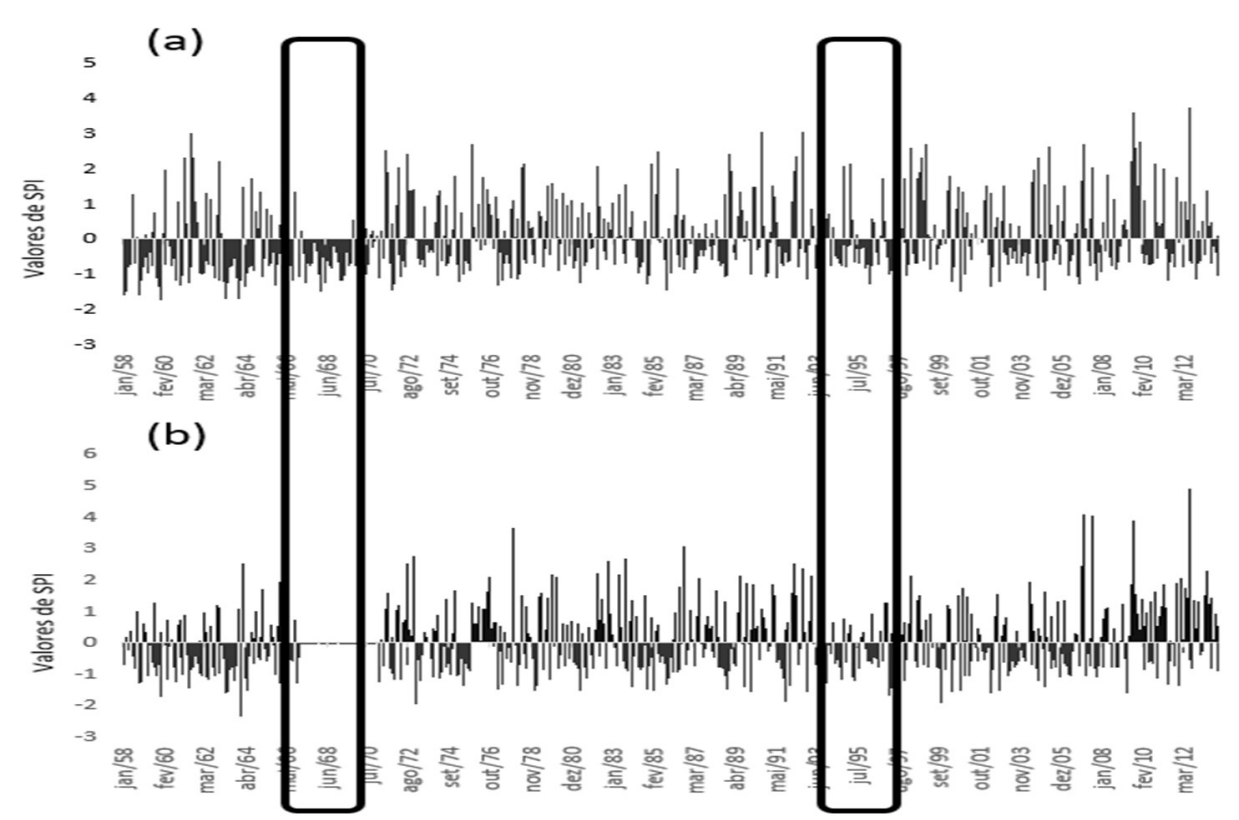

Figura 4: (a) Serie Temporal SPI para Guararapes (SP). (b) Serie Temporal SPI para Queiroz (SP), compreendendo o período de 1958 a 2013).

A distribuição de frequência do SPI para Adamantina (Figura 5a) apresentou um total de $37,5 \%$ de evento de secas, que corresponde a 252 registros. Dentro deste total observado não houve registro de secas extremas (valores de SPI <-2,0) foram observadas 14 ocorrências de seca severa, 66 de seca moderada e 172 de seca leve. Os eventos de chuvas (valores de SPI >0,49), demonstraram-se de menor frequência na estação de Adamantina quando comparado aos eventos de seca. Na distribuição de eventos de chuvas foram notados 69 episódios de chuva leve, 49 de chuva moderada, 30 de chuva severa e 30 de chuva extrema; totalizando 178 ocorrências que corresponde a $26,49 \%$ dos eventos.

Analisando a distribuição de frequência do SPI para Monte Castelo (Figura 5b), foram observadas uma maior frequência de eventos de secas em relação aos eventos de chuvas. Na quantificação dos eventos de secas notaram-se 10 ocorrências de seca severa, 75 de seca moderada e 172 de seca leve; totalizando 257 eventos, que corresponde a 38,24\% de episódios de secas na estação de Monte Castelo. Já para os eventos de chuvas foram apontados 77 episódios de chuva leve, 37 de chuva moderada, 28 de chuva severa e 35 de chuva extrema; totalizando 177 ocorrências, que representa 26,34\% dos eventos. 

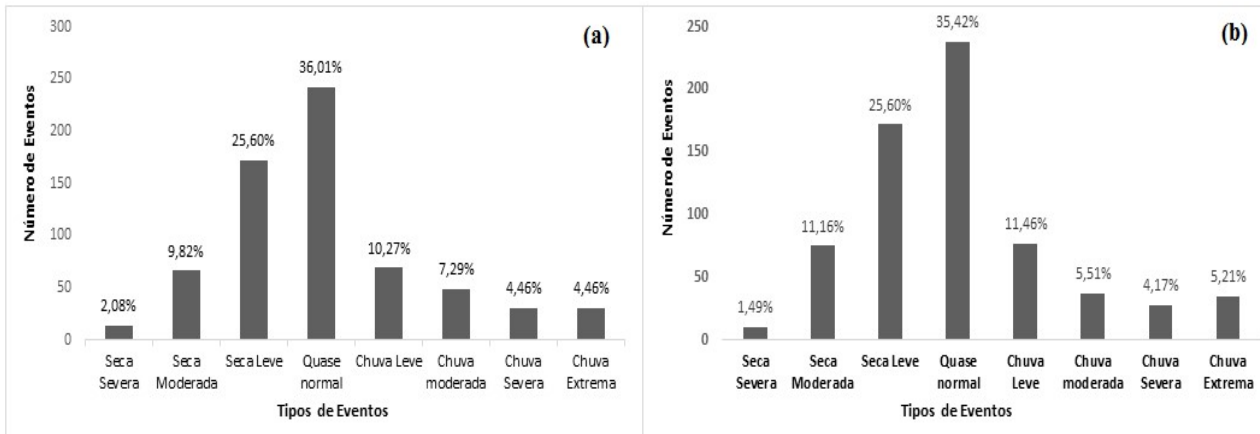

Figura 5: Distribuição de frequência SPI. (a) Adamantina (b) Monte Castelo.

Na análise da série temporal do SPI de Adamantina (Figura 6a), foi constatado pouca ocorrência de períodos prolongados de secas ou chuvas anômalas. O período mais longo de seca ocorreu entre março/1967 a setembro/1969 persistindo por 31 meses. Período este que também pode ser observado na série temporal do SPI para Monte Castelo (Figura 6b), em virtude de ambas as estações possuírem o mesmo comportamento climático conforme (BONFIM et al., 2017b).

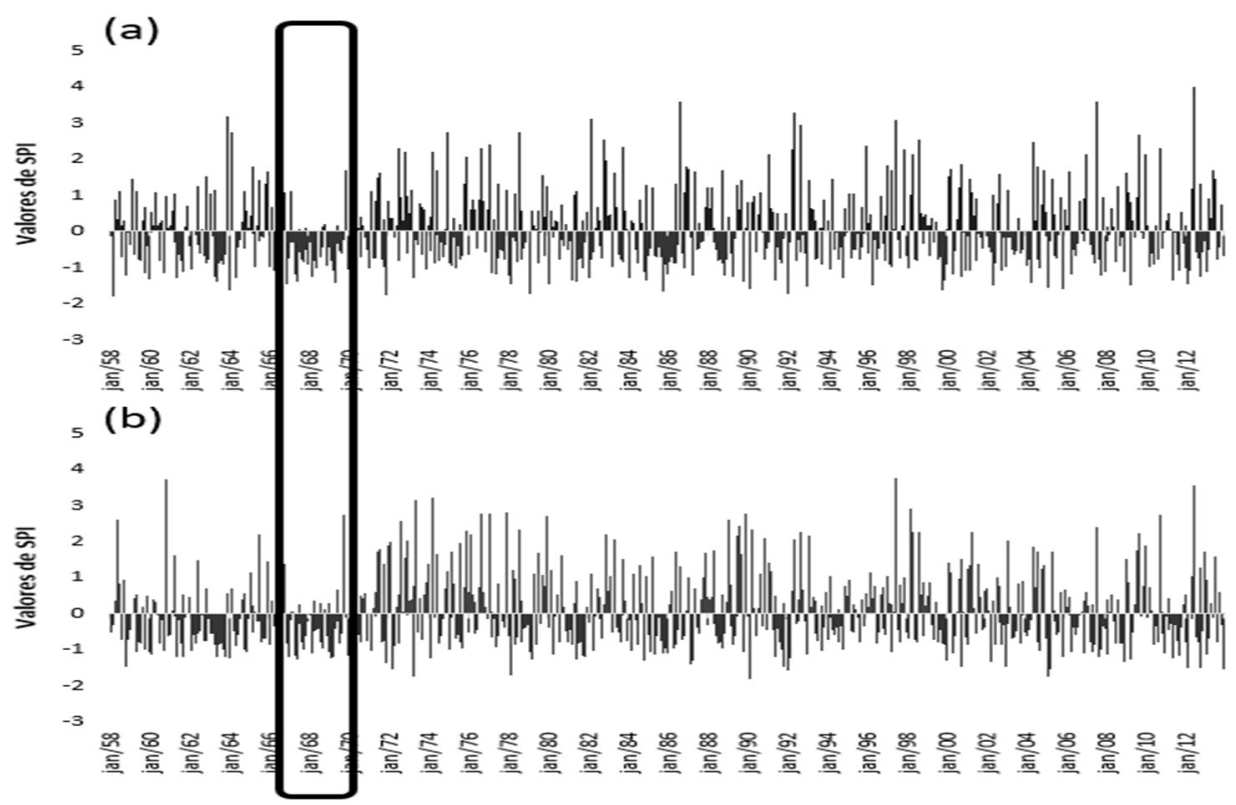

Figura 6: (a) Série Temporal SPI para Adamantina (SP). (b) Série Temporal SPI para Monte Castelo (SP). Compreendendo o período de 1958 a 2013).

Este prolongamento de seca ocorrido nos anos de 1967 a 1969 que afetou as estações pluviométrica de Adamantina e Monte Castelo, ocorreu em consequência da associação entre de ENOS e ODP, na mesma fase (La Niña 1967/68), reduzindo a precipitação (MOLION, 2005; COSTA et al., 2015) e em fases opostas (EI Niño 1968/69) causando anomalias fracas de precipitação (GERSHUNOV et al., 1998; ANDREOLI et al., 2005; SILVA et al., 2012). Os eventos de chuva extrema mais intensos para estação de Monte Castelo ocorreram em outubro/1960, junho/1997 e Junho/2012, em que os valores de SPI $(>2,0)$ foram superiores a 3,5 coincidindo com os valores e períodos encontrados na estação de Adamantina.

Para a cidade de Emilianópolis (Figura 7a), a distribuição de frequência do SPI quantificou 13 episódios de seca severa, 76 de seca moderada e 156 de seca leve, contudo não houve registro de seca extrema; totalizando 245 ocorrências, que corresponde a 36,46\% dos eventos. Os eventos de chuvas foram 
distribuídos em 74 ocorrências de chuva leve, 52 de chuva moderada, 30 de chuva severa e 26 de chuva extrema; totalizando 182 episódios, equivalente a $27,08 \%$ dos eventos.

A distribuição de frequência do SPI para Presidente Venceslau (Figura 7b), apresentou uma maior frequência de eventos de seca, cerca de 37,05\%, que corresponde a 249 registros; distribuídos em 9 eventos de seca severa, 71 de seca moderada e 169 de seca leve. Dentro deste total observado não houve registro de secas extremas (valores de SPI <-2,0). Na distribuição de eventos de chuvas (valores de $\mathrm{SPI}>0,49$ ), foram notados 65 episódios de chuva leve, 41 de chuva moderada, 19 de chuva severa e 37 de chuva extrema; totalizando 162 ocorrências que corresponde a $24,11 \%$ dos eventos.
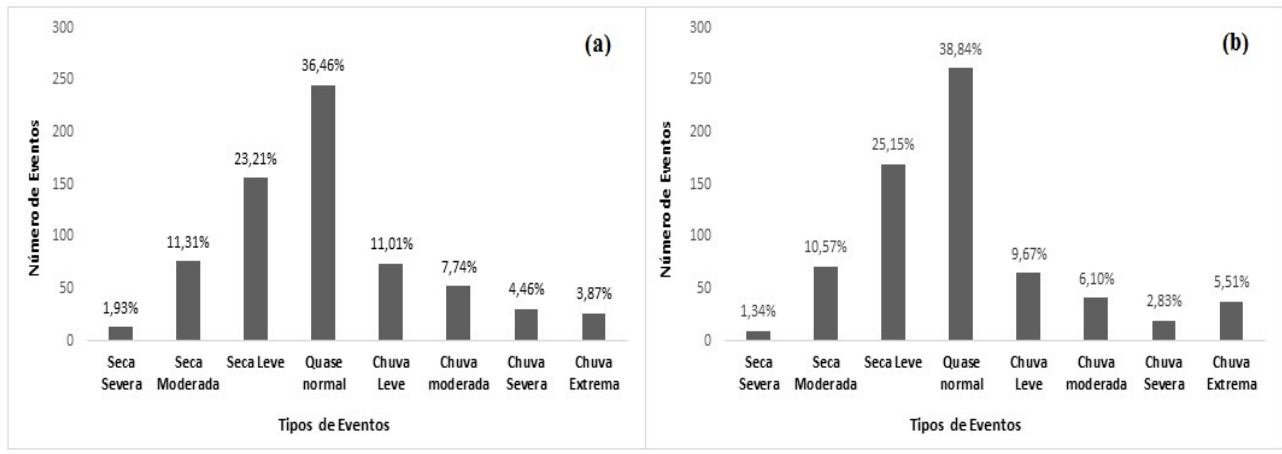

Figura 7: Distribuição de frequência SPI. (a) Emilianópolis (b) Presidente Venceslau.

$\mathrm{Na}$ análise da série temporal do SPI para cidade de Emilianópolis (Figura 8a), um período semi prolongado de chuvas ocorreu entre dezembro/1971 a dezembro/1974, podendo ser visto também na série temporal da cidade de Presidente Venceslau (Figura 8b) entre Julho/1972 a março/1974, em razão destas estações possuírem o mesmo comportamento climático (BONFIM et al., 2017b). Este período chuvoso foi resultado da associação de um El Niño com a ODP em fase positiva, respaldando os trabalhos de Gershunov et al. (1998), Andreoli et al. (2005) e Costa et al. (2015).

Devido à intensa alternância dos escores do SPI, houve impossibilidade de ocorrência de períodos de secas prolongados, como mostrado nos trabalhos de Macedo et al. (2010) e Santos et al. (2017). Foi possível notar um prolongamento de seca entre abril/1993 a dezembro/1994 com duração de 21 meses, tanto para a estação de Emilianópolis como para Presidente Venceslau. Os picos de precipitação extrema na estação de Emilianópolis (Figura 8a) ocorreram em junho/1997 e julho/2007 em que os valores de SPI $(>2,0)$ foram superiores a 3,8. Já para estação de Presidente Venceslau (Figura 8b) os mesmos picos apresentaram valores de 4 e 4,5 respectivamente, mostrando-se mais intensa nesta estação.

Para um melhor entendimento sobre a influência dos tipos de ENOS (Canônico e Modoki) na ocorrência de episódios de chuvas ou secas computado pelo método SPI, a tabela 3 demonstra a quantidade de episódios de seca e chuvas ocorrido de acordo com a configuração e tipo do ENOS no período de 1979 a 2009. As secas severas ocorreram, na maior parte, em anos classificados como La Niña canônica (LNCa), seguidos de anos de El Niño Modoki (ENm). Os anos de ENm reduz a precipitação entre os meses de setembro a fevereiro na região Sudeste do Brasil segundo estudo de Tedeschi et al. (2016). 


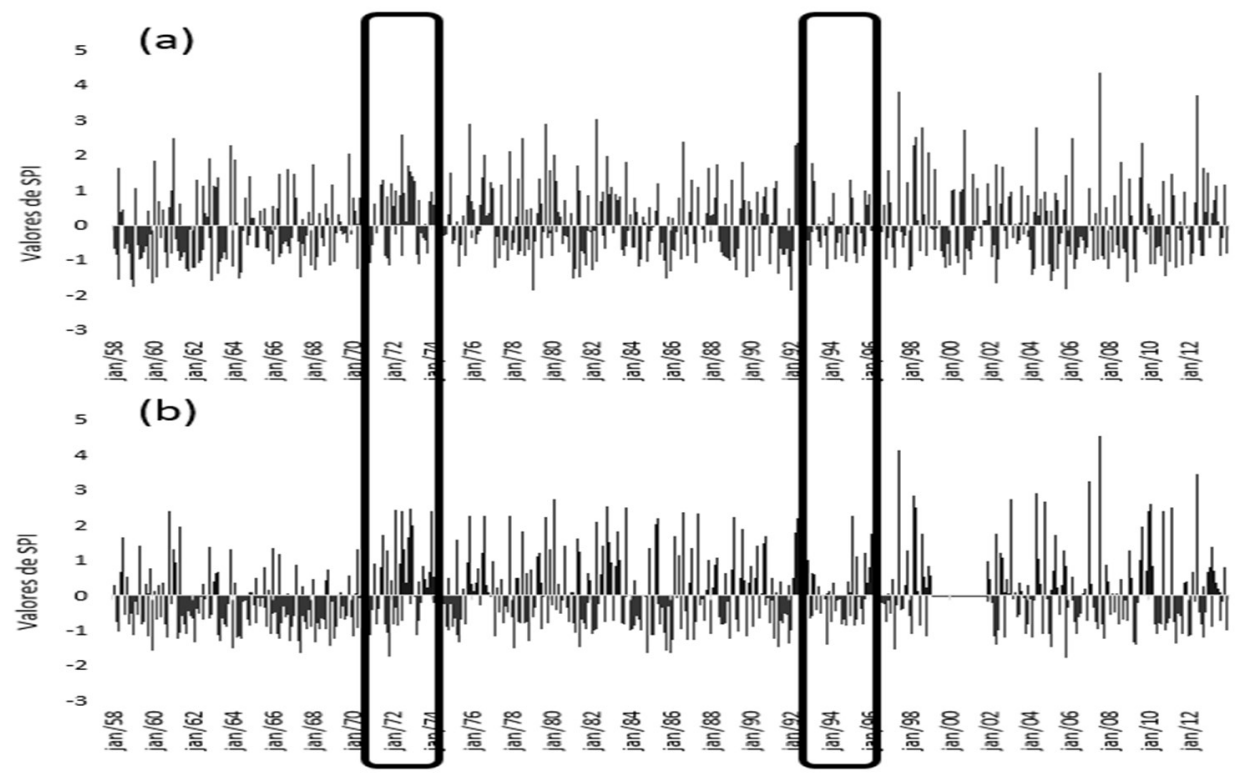

Figura 8: (a) Série Temporal SPI para Emilianópolis (SP). (b) Série Temporal SPI para Presidente Venceslau (SP). Compreendendo o período de 1958 a 2013).

Nos eventos de secas moderadas os anos de LNCa mostraram-se com maior influência, seguidos de anos de La Niña Modoki (LNm), contudo anos de ENm ainda tiveram forte atuação na ocorrência deste tipo de seca. As secas leves ocorreram predominantemente nos anos de LNCa em todas as 8 estações analisadas, corroborando com Tedeschi (2013) e Tedeschi et al. (2016). Os eventos de chuvas (leve, moderada e severa) ocorreram em geral em anos de El Niño Canônico (ENCa), porém os anos de ENm, LNCa e LNm foram participativos para a ocorrência desses episódios de chuvas, a exemplo, a influência de LNm na ocorrência de chuvas moderadas na estação de Guararapes e Queiroz, assim como, ENm para as chuvas de Monte Castelo e Adamantina. Há ressalva para os casos de chuvas extremas que ocorreram predominantemente nos anos de ENCa em todas as estações.

Estes resultados apresentam um possível padrão que conecta o El Niño do tipo canônico com a ocorrência de eventos de chuvas extremas, e também La Niña Canônica para eventos de secas leves, sendo relevante para os estudos de previsões climáticas em virtude de ser capaz de prever episódios de chuvas extremas de acordo com a configuração do ENOS na região do Oceano Pacífico Central.

Os prognósticos climáticos para deteç̧ão de extremos ainda têm tido baixa eficácia devido toda informação sobre esses episódios ter uma incerteza associada (DIAS, 2014). Com intuito de suprir essa falha, a associação entre o índice do SPI e os tipos de ENOS possibilitou um aumento da confiabilidade da previsão mediante a diminuição das incertezas de sua ocorrência. Para a Bacia hidrográfica Aguapeí-Peixe a previsibilidade de ocorrências tanto de secas como de chuvas extremas é uma ferramenta importante para avaliação de riscos e tomada de decisões, para o planejamento e adequação das infraestruturas, principalmente aquelas associadas aos recursos hídricos, para que se possa evitar problemas com demanda de água, vulnerabilidade energética ou prejuízos à população, associados a enchentes e inundações. 
Tabela 3: Ocorrência de eventos de acordo com o tipo de ENOS (período de 1979 a 2009).

\begin{tabular}{|c|c|c|c|c|c|c|c|c|c|}
\hline Evento & ENOS & Adamantina & Bastos & Emilianópolis & Garça & Guararapes & Monte Castelo & Queiroz & P. Venceslau \\
\hline \multirow{4}{*}{ Seca Severa } & ENca & 1 & 0 & 1 & 1 & 0 & 1 & 1 & 0 \\
\hline & ENm & 2 & 1 & 2 & 1 & 1 & 3 & 1 & 0 \\
\hline & LNCa & 3 & 2 & 1 & 2 & 0 & 0 & 3 & 2 \\
\hline & LNm & 1 & 2 & 1 & 2 & 0 & 0 & 3 & 1 \\
\hline \multirow{4}{*}{ Seca Moderada } & ENca & 3 & 5 & 3 & 5 & 4 & 5 & 2 & 3 \\
\hline & ENm & 5 & 6 & 9 & 6 & 3 & 7 & 8 & 8 \\
\hline & LNCa & 9 & 12 & 9 & 4 & 7 & 9 & 8 & 8 \\
\hline & LNm & 11 & 10 & 8 & 5 & 7 & 6 & 6 & 3 \\
\hline \multirow{4}{*}{ seca leve } & ENca & 12 & 9 & 10 & 10 & 13 & 13 & 12 & 12 \\
\hline & ENm & 16 & 20 & 14 & 18 & 20 & 13 & 18 & 16 \\
\hline & LNCa & 25 & 21 & 29 & 28 & 21 & 25 & 27 & 18 \\
\hline & LNm & 14 & 16 & 25 & 17 & 14 & 20 & 20 & 9 \\
\hline \multirow{4}{*}{ chuva leve } & ENca & 11 & 9 & 8 & 5 & 7 & 12 & 14 & 8 \\
\hline & ENm & 8 & 6 & 7 & 3 & 3 & 6 & 9 & 4 \\
\hline & LNCa & 5 & 7 & 8 & 8 & 7 & 8 & 7 & 9 \\
\hline & LNm & 1 & 7 & 2 & 5 & 3 & 7 & 5 & 6 \\
\hline \multirow{4}{*}{ chuva moderada } & ENca & 3 & 4 & 7 & 8 & 5 & 3 & 3 & 8 \\
\hline & ENm & 6 & 4 & 3 & 5 & 2 & 7 & 0 & 3 \\
\hline & LNCa & 4 & 5 & 4 & 4 & 6 & 5 & 5 & 5 \\
\hline & LNm & 4 & 3 & 5 & 5 & 6 & 5 & 8 & 1 \\
\hline \multirow{4}{*}{ chuva severa } & ENca & 9 & 7 & 2 & 3 & 5 & 2 & 5 & 5 \\
\hline & ENm & 4 & 4 & 1 & 3 & 5 & 2 & 5 & 2 \\
\hline & LNCa & 4 & 3 & 2 & 3 & 3 & 2 & 2 & 0 \\
\hline & LNm & 4 & 1 & 3 & 3 & 6 & 2 & 3 & 1 \\
\hline \multirow{4}{*}{ chuva extrema } & ENca & 7 & 7 & 8 & 11 & 7 & 7 & 10 & 8 \\
\hline & ENm & 3 & 2 & 1 & 2 & 5 & 1 & 0 & 3 \\
\hline & LNCa & 1 & 2 & 2 & 3 & 6 & 2 & 1 & 4 \\
\hline & LNm & 2 & 2 & 3 & 2 & 3 & 3 & 1 & 2 \\
\hline
\end{tabular}

\section{CONCLUSÕES}

Na Bacia hidrográfica Aguapeí-Peixe foi constatado uma maior frequência de eventos de secas, contudo a incidência de eventos chuvosos foi mais intensa. Os eventos de chuvas extremas caracterizados pelo SPI ocorrem principalmente em anos de El Niño canônico e eventos de secas leves em anos de La Niña Canônico. A detecção antecipada de sinais de eventos climáticos extremos e o seu monitoramento tornamse um conjunto de informações que visa auxiliar os mais diferentes setores a fim mitigar os impactos que esses fenômenos possam causar a sociedade, priorizando as áreas de riscos e evitando perdas de vidas.

\section{REFERÊNCIAS}

ALVARENGA, L. A.. Precipitação no sudeste brasileiro e sua relação com a Zona de Convergência do Atlântico Sul. Revista Agrogeoambiental, Pouso Alegre, v.4, p.1-7, 2012.

ANDREOLI, R. V.; KAYANO, M. T.. Enso-Related Rainfall Anomalies in South America and Associated Circulation Features During Warm and Cold Pacific Decadal Oscillation Regimes. Internacional Journal Climatology, v.25, n.15, p.2017-2030, 2005. DOI: http://10.1002/joc.1222

ASHOK, K; BEHERA, S. K.; RAO, S. A.; WENG, H.: YAMAGATA T.. El Niño Modoki and its possible teleconnection. Journal of Geophysical Research, v.112, n.C11, p.1-27, 2007. DOI: http://10.1029/2006JC003798

BARRA, T. D. S.; COSTA, J. M. N.; RAO, T. R.; SEDIYAMA, G. C.; FERREIRA, W. P.; DANTAS NETO, F. S.. Caracterização climatológica da severidade de secas do estado do CearáBrasil. Campina grande: Revista Brasileira de Engenharia Agrícola e Ambiental, v.6, n.2, p.266-272, 2002. DOI: http://dx.doi.org/10.1590/S1415-43662002000200015

BLAIN, G. C.; BRUNINI, O.. Análise da escala temporal de monitoramento das secas agrícolas e meteorológicas no Estado de São Paulo. São José dos Campos: Revista
Brasileira de Meteorologia, v.22, n.2, p.255-261, 2007. DOI: http://dx.doi.org/10.1590/S0102-77862007000200010.

BONFIM, O. E. T.; SILVA, D. F.. Identificação de áreas de precipitação homogêneas nas Bacias hidrográficas AguapeíPeixe/SP. In: SIMPÓSIO INTERNACIONAL DE CLIMATOLOGIA 7. Anais. Petrópolis: SIC, 2017a.

BONFIM, O. E. T.; SILVA, D. F.. Utilização do teste MannKendall na avaliação de tendências climáticas nas Bacias hidrográficas Aguapeí-Peixe/SP. In: SIMPÓSIO INTERNACIONAL DE CLIMATOLOGIA, 7. Anais. Petrópolis: SIC, 2017b.

COSTA, J. A.; SILVA D. F.. Ciclos e Períodos de Eventos Extremos na Bacia Hidrográfica do Rio Salgado (CE). In CONGRESSO TÉCNICO E CIENTIFICO DA ENGENHARIA E AGRONOMIA, 1. Anais. Fortaleza, 2015.

DANTAS, A. A. A.; CARVALHO, L. G.; FERREIRA, E.

Classificação e tendências climáticas em Lavras, MG. Revista Ciência e Agrotecnologia, v.31, n.6, p.1862-1866, 2007. DOI: https://dx.doi.org/10.1590/S1413-70542007000600039 
DIAS, M. A. F. S.. Eventos Climáticos extremos. São Paulo: Revista USP, n.103, p.33-40, 2014. DOI:

http://dx.doi.org/10.11606/issn.2316-9036.v0i103p33-40

GERSHUNOV, A.; BARNETT, T. P.. Interdecadal modulation of ENSO teleconnections. Bulletin of the American

Meteorological Society, Boston, v.79, p.2715-2725, 1998.

DOI: https://doi.org/10.1175/1520-

0477(1998)079<2715:IMOET>2.0.CO;2

GRIMM, A. M.. The El Niño impact on the summer monsoon in Brazil: Regional processes versus remote influences. Journal of Climate, Boston, v.16, n.2, p.263-280. 2002. DOI: https://doi.org/10.1175/15200442(2003)016<0263:TENIOT>2.0.CO;2

GRIMM, A. M.; TEDESCHI, R. G.. Influência de eventos EI Niño e La Niña sobre a frequência de eventos extremos de precipitação no Brasil. In: CONGRESSO BRASILEIRO DE METEOROLOGIA, 13. Anais. Fortaleza: SBMET, 2004.

HAYES, M. J.; SVOBODA, M. D.; WILHITE, D. A.; VANYARKHO, O. V.. Monitoring the 1996 drought using the Standardized Precipitation Index. Bulletin of the American Meteorological Society, Boston, v.80, n.3, p.429-438, 1999. DOI:

https://doi.org/10.1175/15200477(1999)080<0429:MTDUTS>2.0.CO;2

KAYANO, M. T.; OLIVEIRA, C. P.. Diferenças associadas à oscilação decenal do Pacífico nas relações interanuais de precipitação na América do Sul e temperatura da superfície do mar. In: JORNADAS CIENTÍFICAS DE LA AME, 30. Anais. Zaragoza, 2008.

LIMA, K. C.; FERNÁNDEZ, J. P. R.. A influência das anomalias de temperatura da superfície do mar e da topografia em dois eventos de precipitação intensa ocorridos no Sudeste do Brasil. Revista Engenharia Ambiental, Espirito Santo dos Pinhais, v.8, n.1, p.309-319, 2011.

MACEDO, M. J. H.; GUEDES, R. V. S.; SOUZA, F. A. S.; DANTAS, F. R. C. Análise do índice padronizado de precipitação para o estado da Paraíba, Brasil. Taubaté: Revista Ambi-Agua, v.5, n.1, p.204-214, 2010. DOI: http://10.4136/ambi-agua.130

MARENGO, J. A.. Água e mudanças climáticas. São Paulo: Estudos avançados, v. 22, n. 63, p. 83-96, 2008. DOI: http://dx.doi.org/10.1590/S0103-40142008000200006

MCKEE, T. B.; DOESKEN, N. J.; KLEIST, J.. The relationship of drought frequency and duration of time scales. In: CONFERENCE ON APPLIED CLIMATOLOGY. Anais. Anaheim: American Meteorological Society, 1993. p.179-186.

MOLION, L. C. B.. Aquecimento global, El Niños, manchas solares, vulcões e Oscilação Decadal do Pacífico. Climanálise, v.3, n.1, p.1-5, 2005.

MUZA, M. N.; CARVALHO, L. M. V.; JONES, C.; LIEBMANN, B.. Intraseasonal and Interannual Variability of Extreme Dry and
Wet Events over Southeastern South America and the Subtropical Atlantic during Austral Summer. Journal of Climate, v.22, n.57, p.1682-1699, 2009. DOI: https://doi.org/10.1175/2008JCLI2257.1

PRESTES, S. D.; SOUSA, A. J. S.; ROLIM, P. A. M.; SANTO, A. R. S. E., SOUSA, J. R. A.. Relações entre a Oscilação decadal do Pacífico e a variabilidade da precipitação em Porto Alegre, RS. In: CONGRESSO BRASILEIRO DE METEOROLOGIA, 16. Anais. Belém, 2010.

ROSEGHINI, W. F. F.. Ocorrência de eventos climáticos extremos e sua repercussão socioambiental no litoral norte paulista. Dissertação (Mestrado em Geografia) -

Universidade Estadual Paulista, Presidente Prudente, 2007.

SANTOS, S. R. Q.; BRAGA, C. C.; SANSIGOLO, C. A.; SANTOS A. P. P.. Determinação de Regiões Homogêneas do Índice de Precipitação Normalizada (SPI) na Amazônia Oriental. Revista Brasileira de Meteorologia, v.32, n.1, p.111-122, 2017. DOI: http://dx.doi.org/10.1590/0102778632120160013

SCHEUREN, J. M; POLAIN, O.; BELOW, R.; GUHA-SAPIR, D.; PONSERRE, S.. Annual Disaster Statistical Review: The Numbers and Trends 2007. Belgium: CRED - Centre for Research on the Epidemiology of Disasters, 2008.

SILVA, D. F.. Análise de aspectos climatológicos, ambientais, agroeconômicos e de seus efeitos sobre a Bacia hidrográfica do rio Mundaú (AL e PE). Tese (Doutorado em Recursos Naturais) - Universidade Federal de Campina Grande, Campina Grande, 2009.

SILVA, D. F.. Previsão hidro-climática para prevenção de desastres naturais no leste do nordeste do brasil utilizando análises estatísticas avançadas. Maceió: CNPq, 2014.

SILVA, D. F.; SOUSA, A. B.; MAIA, L. M.; RUFINO, L. L.. Efeitos da Associação de Eventos de Enos e ODP sobre o Estado do Ceará. Revista de Geografia, v.29, n.2, p.114-135, 2012.

TEDESCHI, R. G. As influências de tipos diferentes de ENOS na precipitação e nos seus eventos extremos sobre a América do Sul. Tese (Doutorado em Meteorologia), Instituto Nacional de Pesquisas Espaciais, São José dos Campos, 2013.

TEDESCHI, R. G.; GRIMM, A.M.; CAVALCANTI, I.F.A. Influence of Central and East ENSO on precipitation and its extreme events in South America during austral autumn and winter. U.K: International Journal of Climatology, v.36, p.47974814, 2016. DOI: http://10.1002/joc.4670

ULIANA, E. M.; REIS, E. F.; SOUZA, A.P.; SILVA, J. G. F.; XAVIER, A. C.. Utilização do índice de precipitação padronizado para a região norte do Estado do Espírito Santo. Revista Irriga, Botucatu, v.20, n.3, p.414-428, 2015. DOI: http://dx.doi.org/10.15809/irriga.2015v20n3p414

A CBPC - Companhia Brasileira de Produção Científica (CNPJ: 11.221.422/0001-03) detém os direitos materiais desta publicação. Os direitos referem-se à publicação do trabalho em qualquer parte do mundo, incluindo os direitos às renovacões, expansões e disseminacões da contribuiç̃o, bem como outros direitos subsidiários. Todos os trabalhos publicados eletronicamente poderão preservam os direitos autorais, mas não têm permissão para a publicação da contribuição em outro meio, impresso ou digital, em português ou em tradução. 